\title{
Coronavirus y anestesia: Consideraciones en torno a la solidaridad
}

\section{Anesthesia and coronavirus: Solidarity issues}

José Ricardo Navarro-Vargas', Álvaro Rodríguez-Roa²

"La mejor defensa contra la peste es huir de ella".

Daniel Defoe en el Diario del año de la peste.

\section{ABSTRACT}

COVID-19 coronavirus infection has led us to reflect on the role of the enormous responsibility that the individual plays within his community for the free enjoyment and enjoyment of life on this planet that belongs to everyone, and the natural cooperation that it must exist between countries to build trust and progress. The WHO declared it a pandemic, and the repercussions of a health and economic emergency have dramatically altered social relations and daily life. The health system has been overwhelmed in high-income countries like Spain and Italy, creating a panorama that ranges from bewilderment to panic. In all the hospitals of the 180 countries that are experiencing this pandemic, the service has been provided with heroism, regardless of the current public health crisis, due to the mercantilist models and the privatization of the system. The high risk of general contagion has not mattered either, there is that large contingent of health workers firm and determined to serve, and anesthesiologists are not far behind. Still, we must be aware that the community needs us, that we must be well informed, and we must take care of ourselves with all the biosecurity measures that this challenge demands. The purpose of this article is to draw attention to these topics, highlighting that the importance of humanity depends on their behavior, their solidarity, and social responsibility.

\section{Key words:}

Anesthesiologist, pandemic, COVID-19, social isolation, quarantine, universal precautions, contagion

\footnotetext{
Decano de Medicina Universidad Nacional de Colombia. Exsecretario Científico de CLASA. Expresidente SCARE.

2 Especialista en Medicina Funcional Tsinghua University Beijin China. Postgrado en Clinical Research: The Harvard Medical School-USA.
}

Fecha de recepción: 15 de marzo de 2020

Fecha de aceptación: 15 de marzo de 2020

\section{ORCID}

https://orcid.org/0000-0003-2548-1325

Correspondencia:

José Ricardo Navarro-Vargas

Email: jrnavarrov@unal.edu.co
Álvaro Rodríguez-Roa

Email: rodriroa@gmail.com 


\section{RESUMEN}

La infección por el coronavirus COVID-19 nos ha puesto a reflexionar en torno al papel de enorme responsabilidad que juega el individuo dentro de su comunidad para el libre disfrute y goce de la vida en este planeta que es de todos, y la cooperación natural que debe existir entre los países para generar confianza y progreso. La OMS la declaró una pandemia y las repercusiones de emergencia sanitaria y económica han alterado de forma dramática las relaciones sociales y la cotidianeidad. El sistema de salud ha sido desbordado en países de altos ingresos como España e Italia, sembrando un panorama que va desde el desconcierto hasta el pánico. En todos los hospitales de los 180 países que cursan con esta pandemia, el servicio se ha venido prestando con heroísmo, sin importar la crisis de salud pública existente, a causa de los modelos mercantilistas y de privatización del sistema. No ha importado tampoco el alto riesgo de contagio general, allí está ese gran contingente de trabajadores de salud firme y decidido a servir, y los anestesiólogos no nos quedamos atrás, pero tenemos que ser conscientes que la comunidad nos necesita, que debemos estar bien informados y debemos cuidarnos con todas las medidas de bioseguridad que exige este reto. El propósito de este artículo es, llamar la atención sobre estos tópicos, destacando que la trascendencia de la humanidad depende de su comportamiento, de su solidaridad y de su responsabilidad social.

\section{Palabras clave:}

Anestesiólogo, pandemia, COVID-19, aislamiento, cuarentena, precauciones universales, contagio

\section{Introducción}

D e acuerdo a una investigación basada en datos gubernamentales de China, el primer caso de contagio de COVID-19, enfermedad causada por el coronavirus SARS-CoV-2 (severe respiratory acute syndrome 2, SARS-CoV-2)[1],[2] ocurrió el 17 de noviembre de 2019, en Wuhan, capital de la provincia de Hubei, China. La infección fue afectando de una a cinco personas hasta llegar a 60 afectados, el 20 de diciembre. Sólo hasta el 5 de enero de 2020 se informó el primer caso por la Comisión de Salud Municipal de Wuhan, refiriendo que había ocurrido el 12 de diciembre. El 11 de enero se anunció la primera muerte en Wuhan y el 21 de enero se informó que la neumonía viral que requería de soporte ventilatorio, se trasmitía entre humanos, lo cual determinó que Wuhan entrara en cuarentena, con aislamiento máximo. El día 30 de enero de 2020 la Organización Mundial de la Salud (OMS), debido el elevado número de casos en China y otros países asiáticos, declara este síndrome una emergencia sanitaria de preocupación internacional; el 11 de marzo de 2020 la OMS lo declaró pandemia, la cual al 23 de marzo ha infectado a 340.000 personas y cobrado la vida a 15.000 de ellas[3].

\section{¿Qué tipo de virus es el COVID-19 y por qué el compromiso en los niños es menor?}

Es un virus de ARN de cadena positiva sencilla no segmentada, que pertenece al género de los betacoronavirus. Se une a través del receptor de la enzima convertidora de angiotensina 2 (ACE2) ubicada en células alveolares tipoll y epitelios intestinales[4].

Este es el mismo receptor utilizado por el SARS (de ahí el nombre técnico del COVID-19, SARS-CoV-2). Desafortunadamente el COVID-19 está mutando, lo cual hace pensar que la virulencia y la trasmisión cambiarán en el tiempo[5].

El receptor ACE2 está presente en los islotes de Langerhans del páncreas, con la posibilidad de afectar el sistema endocrino, mientras que los niños menores de 13 años, pese a que pueden ser trasmisores del virus, se afectan menos porque apenas expresan este tipo de receptor[6].

\section{¿Qué hacer en medio del desconcierto?}

En estos casos de gravedad general, donde el comportamiento y la cultura individual y colectiva determinan la propagación de la enfermedad, la so- 
lidaridad es la mejor estrategia de manejo; se hace necesario un comportamiento personal exigente que comienza con el lavado de manos y el distanciamiento físico, hasta el control absoluto del transporte públi$\mathrm{co}$, el cierre de las fronteras y la cuarentena o acuartelamiento general como actos de sublime deliberación. Desde la salud pública, se debe proceder con autoridad y procurar obtener un diagnóstico precoz mediante el estudio juicioso de los casos sospechosos (verificando procedencia o contacto con individuos infectados), así aún no haya sintomatología[7],[8].

\section{¿Cómo se comporta la enfermedad en el organismo humano?}

La enfermedad viral afecta principalmente las vías respiratorias y cursa con síntomas de fiebre leve a moderada, mialgias, dolor de garganta, tos seca, y en los adultos mayores, síntomas inespecíficos. La muerte es debida a los efectos que produce la tormenta de citoquinas y a miocarditis fulminante[9]. Durante la cascada de citoquinas, la respuesta inmune excesiva produce lesión del tejido pulmonar produciendo disnea, uno de los síntomas premonitorios de complicación respiratoria, aquí se cumple la frase de "nada como un poco de ahogo para aprender el valor del oxígeno"; posteriormente, se presenta falla respiratoria aguda y falla multisistémica. Dentro de los exámenes de laboratorio de mal pronóstico están: elevación de la PCR, LDH, CPK, Dímero D, IL6, elevación de las aminotransferasas, descompensación de la diabetes con acidosis metabólica (cuando existe esta comorbilidad), hiperglicemia, linfopenia (CD4), BNP bajo. A todos los pacientes con COVID-19 graves que requieren hospitalización, se les debe realizar un análisis de ferritina en sangre, puesto que ésta se eleva en la condición de fiebre y tormenta de citoquinas[10].

\section{¿Cómo deben proceder los anestesiólogos?}

El anestesiólogo es quien tiene una mayor implicación de contagiarse por el estrecho contacto con la vía aérea y las gotas en aerosol del paciente infectado, a partir de procedimientos como la ventilación manual, la intubación traqueal, la ventilación mecánica no invasiva, la succión de la vía aérea y procedimientos de fibrolaringoscopia, fibrobroncoscopia y traqueostomía. Por tanto, los cuidados en el manejo de estos pacientes deben ser exhaustivos, iniciando con un lavado de manos y protección con elementos de bioseguridad apropiados, tapabocas o mascarilla facial de alta eficiencia -N95- bata antifluidos, guantes y polainas, protección ocular. Las salas de presión negativa son ideales, pero generalmente no se dispone de ellas; también se pueden usar filtros HEPA portátiles (hign efficiency particle air)[11],[12].

Manejo del paciente infectado que debe ser operado: el protocolo de manejo por parte de los anestesiólogos se debe cumplir con el mayor rigor, mediante una lista de chequeo: Se deben definir las zonas donde está el paciente infectado y su tránsito hacia el quirófano; disponer de los elementos necesarios con carros de paro y de vía aérea; contar con el personal mínimo indispensable, con entrenamiento, donde quien maneja la vía aérea por excelencia debe ser el anestesiólogo, para limitar la manipulación de la vía aérea. Es importante que éste haya realizado previamente simulacros de postura y retiro del equipo de protección personal (EPP) por cuanto puede ser un factor de riesgo de contagio si se hace mal (Figura 1). Todo el personal que atiende al paciente debe utilizar máscara facial de alta eficiencia N95 y protección ocular con monogafas que permitan ajuste elástico o una protección facial completa. La máquina de anestesia debe tener conexión al sistema de desechos de gases medicinales y disponer de doble filtro, entre el paciente y el sistema ventilatorio y en la rama espiratoria cerca al ventilador, ambos filtros deben cambiarse con cada paciente; los parámetros ventilatorios exigen no usar alto flujo de oxígeno, CPAP o BIPAP en el transoperatorio; la intubación se debe realizar con el paciente inconsciente completamente relajado, para minimizar la eventualidad de tos y dispersión de aerosol (forma de diseminación del virus); con este fin se debe realizar una inducción de secuencia rápida; El uso de videolaringoscopia puede evitar colocar la cara del operador cerca del paciente. Durante el mantenimiento se recomienda utilizar volúmenes bajos $\left(6-7 \mathrm{cc} / \mathrm{Kg}\right.$ ), presión entre $20-25 \mathrm{~cm} \mathrm{H}_{2} \mathrm{O}$ y presión pico menor de $35 \mathrm{~cm}$ de $\mathrm{H}_{2} \mathrm{O}[12]$,[13].

Todos los dispositivos no descartables que se utilicen con el paciente (hoja de laringoscopio, guías, bougie, etc.) se deben empacar en una bolsa con sellado hermético para la posterior esterilización. La extubación debe ser suave, para evitar la tos (se recomienda utilizar lidocaína, dexmedetomidina, fentanyl o remifentanil endovenoso); No hay que extubar demasiado temprano (este puede ser un grupo de pacientes donde no es preferible la extubación agresiva). Entre menos profesionales tengan contacto con el paciente menor la oportunidad de contagio[14]-[16].

Algunos protocolos anestésicos recomiendan las técnicas regionales por cuanto el profesional no entra en contacto con la vía aérea del paciente, sin embargo, no todos los procedimientos quirúrgicos se pueden realizar con anestesia regional[14],[17]. 
Figura 1A. Anestesiólogo en simulacro del manejo de vía aérea con lista de chequeo. Cortesía Dr. Javier Osorio, Clínica Shaio, Bogotá Colombia.

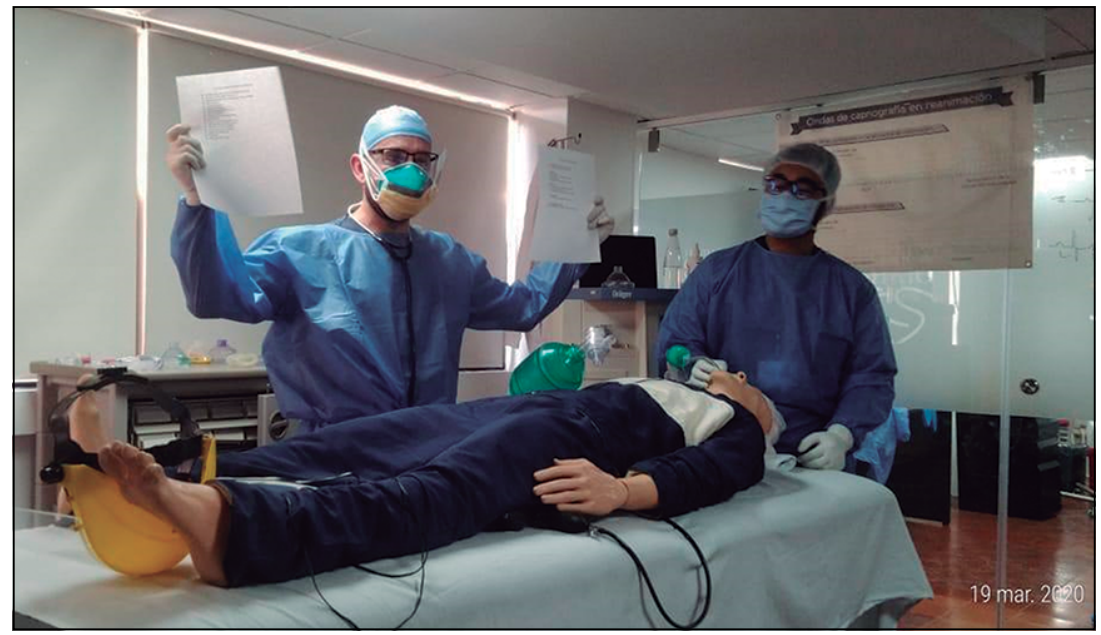

Figura 1B. Anestesiólogo con Equipo de Protección Personal (EPP). Cortesía Dra. Viviana Medina, Hospital Nacional de niños, Benjamín Boom, San Salvador.

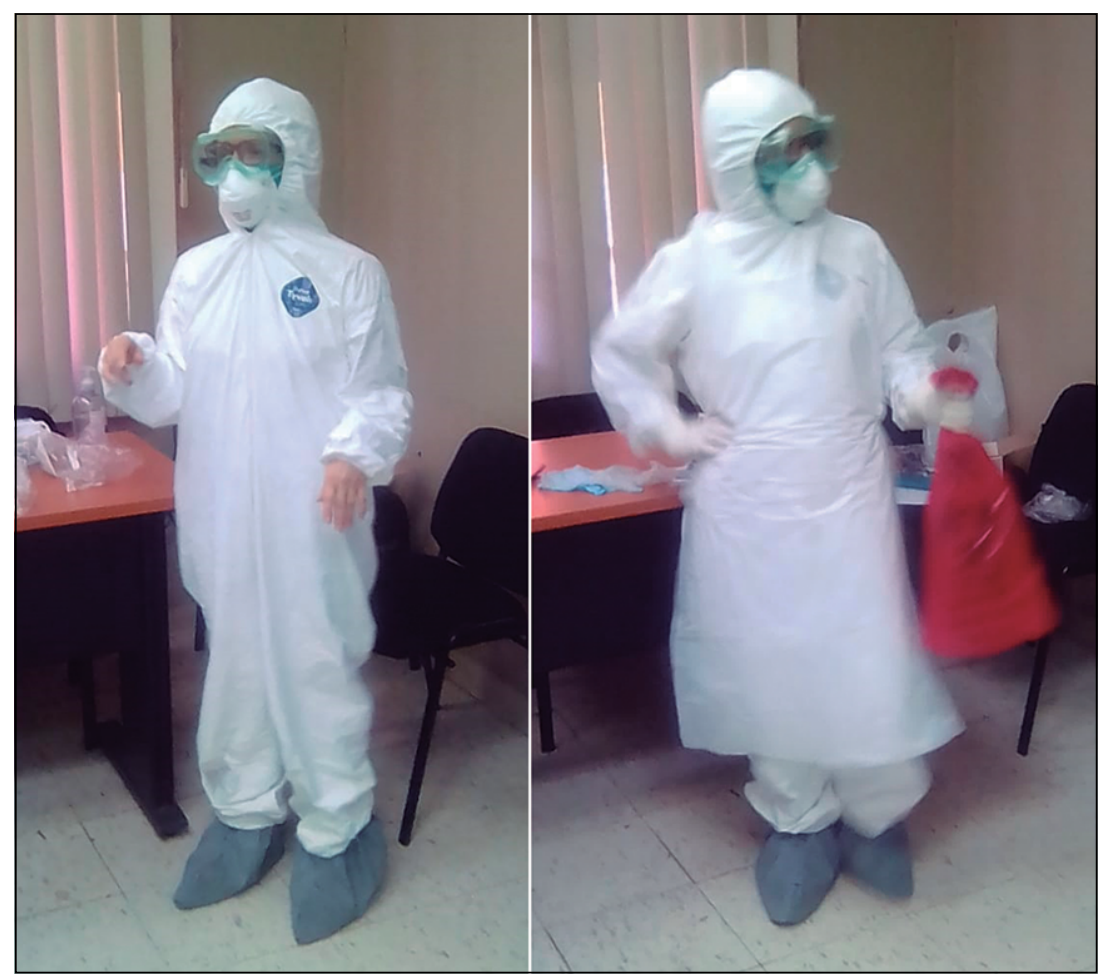

\section{Solidaridad y compromiso con la humanidad,} las mejores estrategias de manejo

Esta enfermedad ha ocasionado una gran mortalidad debido a que no se ha manejado de forma apropiada el control de la exposición a los contactos positivos. De ahí la insistencia hasta la saciedad en que se asuma una responsabilidad humanitaria, de cooperación y de solidaridad, de evitar la exposición, quedarse en casa, lavado de manos constante, no tocarse la cara, la limpieza de las superficies en forma permanente, evitar cualquier tipo de contacto físico; 
si definitivamente hay la probabilidad de haber adquirido la enfermedad, se debe dar alerta al protocolo de manejo de caso sospechoso con aislamiento estricto. Según Harari, el verdadero antídoto contra la epidemia no es la segregación, sino la cooperación[18]. El mismo Harari refiere que la humanidad ha ganado la guerra contra las epidemias porque en la carrera armamentista entre patógenos y médicos, los patógenos dependen de mutaciones ciegas mientras que los médicos confían en el análisis científico de la información; y para vencer una epidemia como ésta, las personas necesitan confiar en expertos científicos, los ciudadanos necesitan confiar en las autoridades públicas y los países confiar entre sí[18].

\section{Posibilidades de manejo médico de la enfermedad}

La evidencia es enfática en que no se cuenta aún con la vacuna (por lo menos la espera es del orden de 1 año o más), y que el tratamiento farmacológico es experimental. Uno de los medicamentos que bloquea la IL6 es el tocilizumab (400 mg en infusión endovenoso, máximo 3 dosis). Cuando se presenta miocarditis fulminante hay una evolución rápida hacia falla cardíaca severa, hipotensión y choque cardiogénico, con tasas de mortalidad entre 50\%-70\%. De ahí que se recomienda prestar atención no solo a las consecuencias de la enfermedad viral en el tejido pulmonar sino también en el tejido miocárdico. Otra opción terapéutica que se cree disminuye la reproducción rápida del virus e interfiere con la transmisividad a otras personas es hidroxicloroquina $400 \mathrm{mg}$ cada 12 horas y luego $200 \mathrm{mg}$ cada 12 horas por 7 días y se le adiciona azitromicina $500 \mathrm{mg}$ al día por 7 días. Este tratamiento no tiene un buen nivel de evidencia y ambos fármacos pueden prolongar el QT[19],[20].

\section{Conclusión}

Cuando enfermedades consideradas pestes como esta pandemia del coronavirus afectan a la humanidad, lo único razonable para controlarla es la solidaridad y la cultura mediante el compromiso férreo de autocuidado personal y colectivo. Hay que aislarse del contagio y tomar todas las medidas para mantener limpias las manos y no tocarse la cara. Las implicaciones de ser considerada una emergencia sanitaria afectan no sólo el estado emocional y físico de las comunidades, sino también la economía de todo el país y del mundo. Una de las mejores apuestas de la inteligencia humana es la previsión, si se recurre a ella con la colaboración de todos se puede controlar esta verdadera hecatombe de salud pública.

\section{Conflicto de intereses}

Los autores manifiestan no tener conflicto de interés alguno.

\section{Referencias}

1. Millán-Oñate J, RodriguezMorales AJ, Camacho-Moreno G, Mendoza-Ramírez $\mathrm{H}$, Rodríguez-Sabogal IA, ÁlvarezMoreno C. A new emerging zoonotic virus of concern: the 2019 novel Coronavirus (COVID-19). Infectio [Internet] Asociacion Colombiana de Infectologia - ACIN; 2020 Apr 15;24(3):187. http://dx.doi. org/10.22354/in.v24i3.848

2. Huang $C$, Wang $Y$, Li $X$, Ren L, Zhao J, Hu Y, et al. Clinical features of patients infected with 2019 novel coronavirus in Wuhan, China. Lancet. 2020
Feb;395(10223):497-506.

https://doi.org/10.1016/

S0140-6736(20)30183-5

PMID:31986264

3. World Health Organization. Statement on the second meeting of the International Health Regulations (2005) Emergency Committee regarding the outbreak of novel coronavirus (2019-nCoV). https:// www.who.int/news-room/ detail/30-01-2020-statementon-the-second-meeting-of-theinternational-health-regulations(2005)-emergency-committeeregarding-the-outbreak-of-novelcoronavirus-(2019-ncov). 2020.

4. Hamming I, Timens $W$, Bulthuis
ML, Lely AT, Navis G, van Goor $H$. Tissue distribution of ACE2 protein, the functional receptor for SARS coronavirus. A first step in understanding SARS pathogenesis. J Pathol. 2004 Jun;203(2):631-7. https:// doi.org/10.1002/path.1570 PMID:15141377

5. Chinese Center for Disease Control and Prevention. Epidemic update and risk assessment of 2019 Novel Coronavirus 2020. http://www. chinacdc.cn/yyrdgz/202001/ P020200128523354919292.pdf

6. Walls AC, Park YJ, Tortorici MA, Wall A, McGuire AT, Veesler D. Structure, Function, 
and Antigenicity of the SARS-

CoV-2 Spike Glycoprotein. Cell. 2020 Apr;181(2):281-292.

e6. https://doi.org/10.1016/j. cell.2020.02.058

PMID:32155444

7. Cetron M, Landwirth J. Public health and ethical considerations in planning for quarantine. Yale J Biol Med. 2005 Oct;78(5):32934. PMID:17132339

8. Wilder-Smith A, Freedman DO. Isolation, quarantine, social distancing and community containment: pivotal role for old-style public health measures in the novel coronavirus (2019nCoV) outbreak. J Travel Med. 2020 Mar;27(2):27. https:// doi.org/10.1093/jtm/taaa020 PMID:32052841

9. Ruan Q, Yang K, Wang W, Jiang $\mathrm{L}$, Song J. Clinical predictors of mortality due to COVID-19 based on an analysis of data of 150 patients from Wuhan, China. Intensive Care Med. 2020 Mar; https://doi.org/10.1007/s00134020-05991-x PMID:32125452

10. Zhu N, Zhang D, Wang W, Li $X$, Yang B, Song J, et al.; China Novel Coronavirus Investigating and Research Team. A novel coronavirus from patients with pneumonia in China, 2019. N Engl J Med. 2020 Feb;382(8):727-33. https://doi. org/10.1056/NEJMoa2001017 PMID:31978945

11. Meng L, Qiu H, Ai Y, Xue Z, Guo
Q, Deshpande R. Intubation and ventilation amid the Covid-19 outbreak.(Published online ahead of print. Anestthesiology. 2020 Mar;2020: https:// doi.org/10.1097/

ALN.0000000000003296 PMID:32195705

12. Brewster D, Chrimes NC, Do T, Fraser K, Groombridge CJ, Higgs $A$, et al. Consensus statement: safe Airway Society principles of airway management and tracheal intubation specific to the COVID-19 adult patient group. Med J Aust. Forthcoming

13. Luo M, Cao S, Wei L, Tang R, Hong S, Liu R, et al. Precautions for Intubating Patients with COVID-19. Anesthesiology. Ovid Technologies (Wolters Kluwer Health); 2020 Mar;1. http://dx.doi.org/10.1097/ aln.0000000000003288

14. 14 Borrero C, Escobar B. Protocolo para manejo de casos probables o confirmados de covid-19. Salas de cirugía/ Hospital Universitario Nacional de Colombia. Bogotá ColombiaSuramérica, marzo de 2020

15. Caputo KM, Byrick R, Chapman $M G$, Orser BJ, Orser BA. Intubation of SARS patients: infection and perspectives of healthcare workers. Can J Anaesth. 2006 Feb;53(2):122-9. https://doi.org/10.1007/ BF03021815 PMID:16434750

16. Peng $W H$, Ho PL, Hota SS.
Outbreak of a new coronavirus: what anaesthetists should know. BJA 2020, article in press. https://bjanaesthesia.org/ article/S0007-0912(20)30098-2/ pdf https://doi.org/10.1016/j. bja.2020.02.008.

17. Poon LC, Yang $\mathrm{H}$, Lee JCS, Copel JA, Leung TY, Zhang Y, et al. ISUOG Interim Guidance on 2019 novel coronavirus infection during pregnancy and puerperium: information for healthcare professionals. Ultrasound in Obstetrics \& Gynecology [Internet]. Wiley; 2020 Mar 11; Available from: http://dx.doi.org/10.1002/ uog. 22013

18. Harari YN. En la batalla contra el coronavirus, la humanidad carece de liderazgo. Time, 15 marzo de 2020

19. Vélez JD. Tratamiento de infección por coronavirus (Covid-19). Protocolo Fundación Clínica Valle del Lilí, Cali Colombia- Suramérica, marzo 2020.

20. Gautret $P$, Lagier J-C, Parola $P$, Hoang VT, Meddeb L, Mailhe $M$, et al. Hydroxychloroquine and azithromycin as a treatment of COVID-19: results of an open-label non-randomized clinical trial. International Journal of Antimicrobial Agents. Elsevier BV; 2020 Mar;105949. http://dx.doi.org/10.1016/j. ijantimicag.2020.105949 